\title{
ВЛИЯНИЕ ХВОЙНОГО ПРЕПАРАТА НА РОСТ И ЭЛЕМЕНТНЫЙ СОСТАВ CЕЯНЦЕВ PINUS SYLVESTRIS L. В УСЛОВИЯХ ЛЕСНОГО ПИТОМНИКА
}

\author{
(C) А.В. Егорова , Н.П. Чернобровкина, Е.В. Робонен \\ Институт леса Карельского научного центра РАН, ул. Пушкинская, 11, \\ Петрозаводск, 185910 (Россия), e-mail: egorova.anast@mail.ru
}

\begin{abstract}
Проведено испытание хвойного препарата производства Тихвинского химического завода на рост и накопление элементов минерального питания у двухлетних сеянцев сосны обыкновенной при выращивании в лесном питомнике в условиях открытого грунта. Выявлено стимулирующее действие препарата на рост растений при внесении в дозах 0,03 мл м $^{-2}, 0,1$ и 0,3 мл $\cdot \mathrm{M}^{-2}$. Максимальный положительный эффект наблюдался при дозе 0,3 мл $\cdot \mathrm{M}^{-2}$. Масса хвои в этом варианте опыта была выше на $121 \%$, масса сеянца - на 109\%, а линейные параметры - в 1,5 раза по сравнению с контрольными растениями. Под воздействием препарата увеличивался вынос большинства химических элементов и их накопление в органах сеянцев. Исключение составили марганец по накоплению в стволиках и корнях и железо в стволиках. Хвойный препарат в стимулирующих рост растений дозах оказал неоднозначное влияние на элементный состав органов сеянцев в расчете на единицу сухого вещества. Отмечалось повышение или тенденция к повышению уровня фосфора в органах, калия в хвое и корнях, меди - в стволиках и корнях, а кальция, цинка и магния - в хвое. Внесение хвойного препарата в дозах 0,03 мл $\mathrm{m}^{-2}, 0,1$ и 0,3 мл' ${ }^{-2}$ приводило к понижению значений соотношения N/P в хвое и стволиках, а также изменяло соотношение N/P/K в хвое сеянцев сосны за счет увеличения доли фосфора, что свидетельствовало об оптимизации статуса фосфора у растений. Хвойный препарат можно рекомендовать для применения в лесных питомниках в качестве эффективного стимулятора роста при выращивании посадочного материала хвойных пород.
\end{abstract}

Ключевые слова: Pinus sylvestris L., сеянцы, рост, регуляторы роста, элементный состав, хвойный препарат, корневая подкормка, лесной питомник.

Работа выполнена в рамках проекта № 0220-2014-0009 по государственному заданию ИЛ КарНЦ РАН.

\section{Введение}

Технология выращивания высококачественного посадочного материала для искусственного лесовосстановления предусматривает использование регуляторов роста на различных этапах вегетации. Использование современных физиологически активных веществ в качестве корневых и внекорневых подкормок при выращивании сеянцев хвойных пород значительно стимулирует рост и повышает их качество $[1,2]$. Среди наиболее изученных препаратов следует отметить циркон, крезацин, эпин-экстра, фумар, агат-25К, альбит, гумат, эпин, которые при малых дозах оказывают положительное воздействие на всхожесть семян и рост сеянцев хвойных пород, способствуют лучшему развитию корневой системы, повышению накопления биомассы, тем самым позволяя увеличивать выход посадочного материала и снижать затраты на его выращивание [3-11]. При однократном воздействии стимуляторами положительный эффект на рост сеянцев сохраняется в течение всего срока выращивания [6]. Крезацин и Агат-25 в качестве внекорневой подкормки сеянцев сосны обыкновенной (Pinus sylvestris L.) повышали биомассу растений в 1,5-2 раза по отношению к контролю [2]. Внекорневая обработка сеянцев сосны юньнаньской (Рinus

Егорова Анастасия Васильевна - аспирант, e-mail: egorova.anast@mail.ru

Чернобровкина Надежда Петровна - доктор биологических наук, ведущий научный сотрудник, доцент, e-mail: chernobr@krc.karelia.ru Робонен Елена Вильямовна - ведущий физик, e-mail: er51@bk.ru yunnanensis Franch.) ауксинами (ИУК и ИМК) положительно влияла на их рост [1].

Однако большинство специалистов лесных питомников отказываются от применения стимуляторов роста из-за недоступности препаратов, строгих норм приготовления растворов и обработки се-

\footnotetext{
* Автор, с которым следует вести переписку.
} 
мян. Необходима разработка доступного стимулятора роста, обладающего большим диапазоном эффективных концентраций, исключающего возможность отрицательных последствий при неправильном разведении, нетоксичного, дешевого и экологически безопасного [12].

В последнее время возрастает тенденция к использованию препаратов, полученных из природных источников, в частности из растительного сырья. Изучение механизмов самозащиты растений в природе привело к разработке новых природных, экологически безопасных биостимуляторов. Однако рекомендованы они в основном для использования в сельском хозяйстве. Воздействие их на древесные породы практически не изучено.

Все более актуальным становится вопрос о рациональном использовании древесного сырья [13-15]. Особый интерес представляет древесная зелень хвойных пород, являющаяся потенциальным сырьем для производства биологически активных препаратов. Компоненты, входящие в ее состав, активно участвуют в обмене веществ растительного организма [16-20]. Значительное стимулирующее воздействие на всхожесть семян и рост проростков сосны китайской (Pinus tabulaeformis Carr.) оказали растворы, полученные разбавлением 0,01 и $0,02 \Gamma^{\cdot}$ мл $^{-1}$ маточных экстрактов (гидромодуль $1: 10$ ) корня и опада сосны китайской различного возраста [21]. Положительное влияние хвойного водного экстракта на накопление сухой массы 15-дневных проростков сосны обыкновенной выявлено при использовании растительного сырья, заготовленного с учетом суточной динамики содержания регуляторов роста в хвое [22, 23]. Установлено, что натриевые соединения природных терпеноидов, полученные из пихты, ели и березы, могут оказывать на растения стимулирующее действие [24]. На основании концентратов натриевых, калиевых и медных солей кислот, выделенных из древесной зелени пихты, получены стимуляторы роста, оказывающие ростостимулирующее, фунгицидное, инсектицидное и бактерицидное действие [25]. Активно исследуются биопрепараты на основе тритерпеновых кислот пихты сибирской, таких как СИЛК (Новосил), Вэрва, Биосил, показано их ростостимулирующее и защитное действие [26, 27]. Разработана технология комплексной переработки древесной зелени и коры пихты сибирской с получением биопрепаратов [28]. Отмечается предпочтительность использования природных препаратов в экологическом аспекте. Разработанный на базе Тихвинского химзавода хвойный препарат из древесной зелени сосны и ели, в состав которых входят хлорофилло-каротиновая паста, хвойный экстракт и хвойное эфирное масло, хорошо зарекомендовал себя при выращивании сельскохозяйственных культур.

Цель настоящей работы - испытание хвойного биопрепарата производства Тихвинского химзавода в качестве стимулятора роста при выращивании посадочного материала хвойных пород.

\section{Экспериментальная часть}

Предметом исследования был хвойный препарат производства Тихвинского химзавода, приготовленный из хвои сосны и ели и состоящий из хлорофилло-каротиновой пасты, которая содержит витамин А и повышает обмен веществ и иммунитет растений; хвойного экстракта, содержащего азотные соединения, углеводы, витамины С, В1, В2, В6, РР, Н, растительные гормоны и фолиевую кислоту, хвойное эфирное масло, обладающее антимикробным и инсектицидным действием. Препарат также содержит макро- и микроэлементы, экстрагируемые из хвои [29].

Испытания ростостимулирующих свойств хвойного препарата проводили на двухлетних сеянцах сосны обыкновенной (Pinus sylvestris L.), выращиваемых в лесном питомнике «Вилга» в условиях открытого грунта на территории южной Карелии. Супесчаные почвы питомника характеризовались оптимальной для интенсивного роста сеянцев хвойных растений кислотностью - рНсол. 5,2 \pm 0,47, но дефицитным содержанием элементов минерального питания. В пахотном горизонте почвы содержание гумуса составило $2,1 \pm 0,2 \%$ от сухой почвы, $\mathrm{NO}_{3}+\mathrm{NH}_{4}-0,13 \pm 0,01, \mathrm{P}_{2} \mathrm{O}_{5}-0,01 \pm 0,001, \mathrm{~K}_{2} \mathrm{O}-0,004 \pm 0,0003, \mathrm{Ca}-$ $0,29 \pm 0,03, \mathrm{~B}-0,0007 \pm 0,00008, \mathrm{Cu}-0,004 \pm 0,0004, \mathrm{Mn}-0,019 \pm 0,002, \mathrm{Zn}-0,002 \pm 0,0002 \%$ от сухой почвы. Было заложено пять вариантов опыта. Для каждого варианта были выбраны изолированные участки площадью 1,6 м² в трех повторностях. Варианты опыта отличались дозой вносимого в почву хвойного препарата: 0,03 мл м $^{-2} ; 0,1 ; 0,3 ; 1$ мл м $^{-2}$ и 0 (контроль). В качестве контроля использовали воду. Корневую подкормку хвойным препаратом проводили в первую декаду июня в сухую погоду. Далее сеянцы выращивали в производственных условиях по стандартной технологии. 
В конце вегетационного сезона сеянцы выкапывали, корни промывали водой. Растения разделяли на хвою, стволики и корни, измеряли их биометрические показатели - высоту сеянца, длину корней и диаметр корневой шейки. Затем растительный материал высушивали в термостате при $105{ }^{\circ} \mathrm{C}$ до постоянного веса, определяли абсолютно сухую массу. Анализ содержания макро- и микроэлементов в растениях и почве проводили общепринятым методом [30].

Математическую обработку данных осуществляли с помощью общепринятых методов статистики с использованием пакета программ Microsoft Excel $[31,32]$. Результаты представлены в виде средних арифметических значений и их стандартных ошибок. Данные получены с использованием оборудования ЦКП «Аналитическая лаборатория» ИЛ КарНЦ РАН.

\section{Обсуждение результатов}

Результаты испытания хвойного препарата производства Тихвинского химического завода на рост сеянцев сосны обыкновенной второго года жизни показали стимулирующий эффект при использовании его в дозах 0,$03 ; 0,1 ; 0,3$ мл· $\mathrm{M}^{-2}$ (рис. 1). Доза хвойного препарата 1,0 мл $\mathrm{M}^{-2}$ не оказывала стимулирующего влияния на рост сеянцев. Максимальный эффект от действия препарата наблюдался при дозе внесения 0,3 мл $\cdot \mathrm{M}^{-2}$. У опытных сеянцев, по сравнению с контрольными, увеличивалась высота, длина корней и особенно значительно диаметр корневой шейки, максимально в 1,5 раза. Масса органов сеянцев также значительно увеличивалась под воздействием препарата. При дозе 0,3 мл $\mathbf{m}^{-2}$ масса хвои, стволиков, корней и сеянца увеличивалась до 2 раз. Соотношение масс надземной и подземной частей сеянца достоверно повышалось, за счет значительного увеличения массы хвои, лишь при внесении препарата в дозе 0,3 мл· $\mathrm{M}^{-2}$, превосходя контрольный уровень на $15 \%$. Масса стволиков под воздействием препарата в дозах 0,1 и 0,3 мл м $^{-2}$ изменялась меньше, чем масса корней и особенно хвои. Изменение соотношения частей сеянцев сосны обыкновенной и ели обыкновенной (Picea abies (L.) Karst.), преимущественно за счет увеличения масс хвои и корней при относительном постоянстве массы стволиков, наблюдали также в экспериментах с повышением питательной ценности грунта [33].

Внесение хвойного препарата в дозах $0,03,0,1$ и 0,3 мл м $^{-2}$ оказало неоднозначное влияние на содержание макро- и микроэлементов в органах сеянцев сосны (табл. 1, 2). Оптимальным для сеянцев сосны считается содержание азота в хвое 2,4-3,0\%, фосфора - 0,15-0,4\%, калия - 0,9-1,6\% [34]. В хвое контрольных сеянцев уровень азота и фосфора был низким, а калия - в пределах оптимума. Под воздействием хвойного препарата содержание азота в расчете на единицу сухого вещества в органах сеянцев сосны не изменялось. Содержание фосфора во всех органах сеянцев и калия в хвое и корнях в расчете на единицу сухого вещества преимущественно имело тенденцию к повышению под воздействием препарата.

Оптимальным для сеянцев сосны считается соотношение N/P, равное 8-9, с незначительными различиями по органам [35]. Результаты наших исследований показали, что более высокие значения N/P наблюдаются в контрольном варианте во всех органах сеянцев сосны, кроме корней, а также при внесении повышенной дозы препарата - 1,0 мл ${ }^{-2}{ }^{-2}$. Внесение хвойного препарата в дозах 0,03, 0,1 и 0,3 мл• ${ }^{-2}$ способствовало понижению значений соотношения N/P в хвое и стволиках сеянцев до уровня оптимальных за счет увеличения доли фосфора.

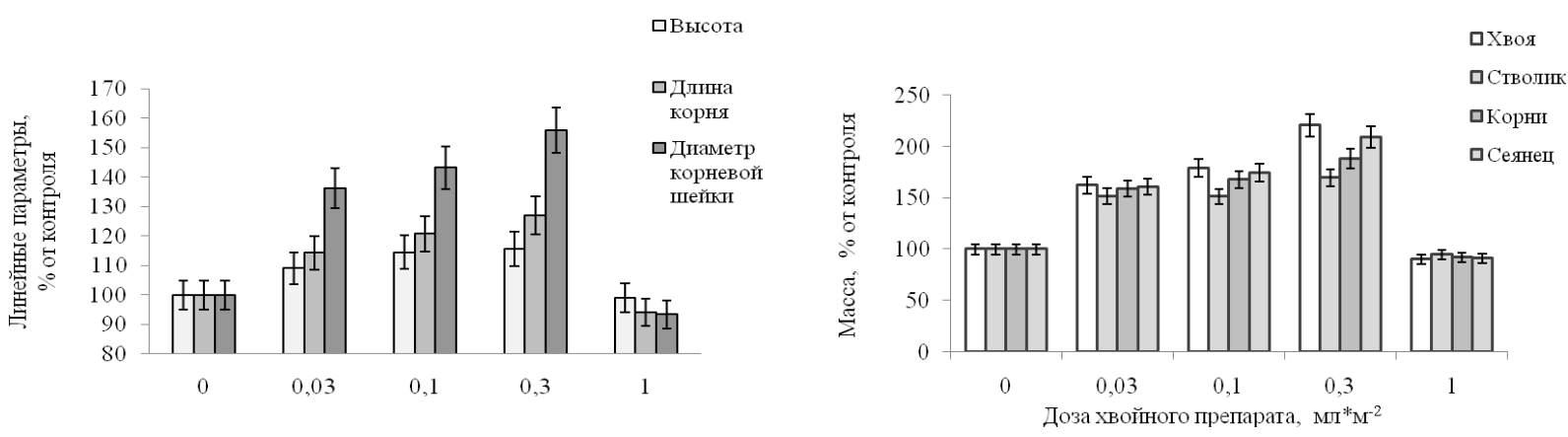

Рис. 1. Влияние хвойного препарата на биометрические показатели органов двухлетних сеянцев сосны обыкновенной, процент от контроля 
Таблица 1. Влияние хвойного препарата на содержание макроэлементов в органах двухлетних сеянцев сосны обыкновенной

\begin{tabular}{|c|c|c|c|c|c|c|}
\hline $\begin{array}{c}\text { Орган расте- } \\
\text { ния }\end{array}$ & $\begin{array}{c}\text { Доза хвойного } \\
\text { препарата, } \\
\text { мл·м }\end{array}$ & $\mathrm{N}, \%$ & $\mathrm{P}, \%$ & $\mathrm{~K}, \%$ & $\mathrm{~N} / \mathrm{P}$ & $\mathrm{N} / \mathrm{P} / \mathrm{K}$ \\
\hline \multirow{5}{*}{ Хвоя } & 0 & $1,93 \pm 0,2$ & $0,13 \pm 0,01$ & $1,44 \pm 0,1$ & 14 & $55: 4: 41$ \\
\hline & 0,03 & $2,00 \pm 0,2$ & $0,17 \pm 0,02$ & $1,58 \pm 0,1$ & 12 & $53: 5: 42$ \\
\hline & 0,1 & $1,89 \pm 0,2$ & $0,2 \pm 0,02$ & $1,77 \pm 0,2$ & 10 & $49: 5: 46$ \\
\hline & 0,3 & $1,98 \pm 0,2$ & $0,21 \pm 0,02$ & $1,32 \pm 0,1$ & 10 & $57: 5: 38$ \\
\hline & 1 & $2,14 \pm 0,2$ & $0,14 \pm 0,1$ & $1,17 \pm 0,1$ & 16 & $62: 4: 34$ \\
\hline \multirow{5}{*}{ Стволик } & 0 & $1,24 \pm 0,1$ & $0,09 \pm 0,01$ & $0,62 \pm 0,06$ & 14 & $63: 5: 32$ \\
\hline & 0,03 & $1,27 \pm 0,1$ & $0,12 \pm 0,01$ & $0,59 \pm 0,06$ & 10 & $64: 6: 30$ \\
\hline & 0,1 & $1,02 \pm 0,1$ & $0,12 \pm 0,01$ & $0,69 \pm 0,06$ & 8 & $55: 7: 38$ \\
\hline & 0,3 & $1,01 \pm 0,1$ & $0,10 \pm 0,01$ & $0,60 \pm 0,06$ & 10 & $59: 6: 35$ \\
\hline & 1 & $1,16 \pm 0,1$ & $0,10 \pm 0,01$ & $0,60 \pm 0,06$ & 11 & $62: 6: 32$ \\
\hline \multirow{5}{*}{ Корни } & 0 & $1,40 \pm 0,1$ & $0,15 \pm 0,1$ & $1,25 \pm 0,1$ & 8 & $50: 6: 44$ \\
\hline & 0,03 & $1,48 \pm 0,1$ & $0,17 \pm 0,02$ & $1,33 \pm 0,1$ & 8 & $50: 6: 44$ \\
\hline & 0,1 & $1,43 \pm 0,1$ & $0,21 \pm 0,02$ & $1,42 \pm 0,1$ & 7 & $47: 7: 46$ \\
\hline & 0,3 & $1,41 \pm 0,1$ & $0,17 \pm 0,02$ & $1,08 \pm 0,1$ & 8 & $53: 6: 41$ \\
\hline & 1 & $1,49 \pm 0,1$ & $0,15 \pm 0,01$ & $1,00 \pm 0,1$ & 11 & $60: 5: 35$ \\
\hline
\end{tabular}

Таблица 2. Влияние хвойного препарата на содержание химических элементов в органах двухлетних сеянцев сосны обыкновенной (мг/кг)

\begin{tabular}{c|c|c|c|c|c|c|c}
\hline $\begin{array}{c}\text { Орган рас- } \\
\text { тения }\end{array}$ & $\begin{array}{c}\text { Доза хвой- } \\
\text { ного препа- } \\
\text { рата, мл·м }\end{array}$ & $\mathrm{Ca}$ & $\mathrm{Mg}$ & $\mathrm{Fe}$ & $\mathrm{Mn}$ & $\mathrm{Zn}$ & $\mathrm{Cu}$ \\
\hline \multirow{5}{*}{ Хвоя } & 0 & $2366 \pm 243,0$ & $729 \pm 71,8$ & $578 \pm 56,8$ & $130 \pm 12,3$ & $33 \pm 3,1$ & $12 \pm 1,1$ \\
& 0,03 & $3001 \pm 308,0$ & $796 \pm 76,4$ & $608 \pm 61,3$ & $133 \pm 12,7$ & $43 \pm 4,6$ & $12 \pm 1,2$ \\
& 0,1 & $3086 \pm 300,0$ & $828 \pm 79,8$ & $497 \pm 48,8$ & $132 \pm 14,2$ & $40 \pm 3,8$ & $10 \pm 1,0$ \\
& 0,3 & $3142 \pm 319,0$ & $814 \pm 80,3$ & $518 \pm 52,3$ & $127 \pm 13,1$ & $40 \pm 3,7$ & $12 \pm 1,4$ \\
& 1 & $4048 \pm 398,0$ & $845 \pm 82,6$ & $593 \pm 60,3$ & $117 \pm 10,9$ & $34 \pm 3,0$ & $9 \pm 1,2$ \\
\hline \multirow{3}{*}{ Стволик } & 0 & $1900 \pm 187,0$ & $590 \pm 58,7$ & $341 \pm 35,2$ & $83 \pm 8,8$ & $35 \pm 3,2$ & $9 \pm 1,1$ \\
& 0,03 & $1673 \pm 154,0$ & $554 \pm 54,2$ & $205 \pm 21,4$ & $51 \pm 4,9$ & $36 \pm 3,9$ & $11 \pm 1,2$ \\
& 0,1 & $1641 \pm 159,0$ & $603 \pm 60,9$ & $243 \pm 25,6$ & $54 \pm 5,3$ & $39 \pm 4,3$ & $14 \pm 1,3$ \\
& 1 & $1534 \pm 148,0$ & $502 \pm 49,4$ & $211 \pm 20,8$ & $58 \pm 5,1$ & $36 \pm 3,7$ & $10 \pm 1,1$ \\
& 0 & $2257 \pm 231,0$ & $604 \pm 59,1$ & $282 \pm 27,7$ & $75 \pm 6,8$ & $32 \pm 3,1$ & $10 \pm 1,0$ \\
\hline \multirow{3}{*}{ Корни } & 0,03 & $1324 \pm 126,0$ & $758 \pm 76,7$ & $1181 \pm 121,1$ & $86 \pm 8,9$ & $43 \pm 3,8$ & $10 \pm 0,9$ \\
& 0,1 & $1677 \pm 171,0$ & $776 \pm 74,4$ & $1341 \pm 135,3$ & $61 \pm 5,8$ & $43 \pm 4,3$ & $15 \pm 1,7$ \\
& 0,3 & $1398 \pm 132,0$ & $729 \pm 71,9$ & $1157 \pm 114,5$ & $66 \pm 6,6$ & $40 \pm 4,1$ & $13 \pm 1,4$ \\
& 1 & $1328 \pm 125,0$ & $750 \pm 76,1$ & $913 \pm 92,0$ & $80 \pm 7,4$ & $39 \pm 3,9$ & $9 \pm 0,8$ \\
\hline
\end{tabular}

Оптимум соотношения N/P/K у растений подразделяют на «хозяйственный» и внутренний (биологический) [36]. «Хозяйственный» оптимум N/P/K определяется как соотношение элементов питания в среде, которое обеспечивает формирование максимальной биомассы растений. При биологическом оптимуме соотношение элементов в растении и среде одинаково, и это обеспечивает им наиболее благоприятное развитие. Оптимальные значения соотношения N/P/K в хвое сосны обыкновенной составляют для «хозяйственного» и внутреннего оптимумов соответственно $53: 28: 19$ и $55: 8: 37$ [37]. Отмечается постоянство соотношения N/P/K в хвое деревьев сосны обыкновенной и ели европейской разного возраста при неизменных условиях произрастания [38]. Соотношение N/P/K по доле азота и калия изменяется у сосны и ели в процессе развития хвои от почки до двухлетней хвои.

В хвое исследуемых контрольных сеянцев сосны обыкновенной соотношение N/P/K было близким к внутреннему оптимуму по азоту, пониженным - по фосфору и повышенным - по калию (табл. 1). Под воздействием хвойного препарата в дозах 0,1 и 0,3 мл м $^{-2}$ изменялось соотношение N/P/K в хвое в пользу фосфора, что приближало значения по фосфору к оптимальным. Отмечалось, что увеличение интенсивности роста сосны под воздействием изменения условий минерального питания происходило также в большей степени за счет увеличения в хвое доли фосфора в соотношении N/P/K [37]. 
Соотношение N/P/K в стволиках контрольных растений отличалось более высокой долей азота и более низкой - калия, а в корнях доли азота и калия были близкими к значениям по хвое. По доле фосфора в соотношении N/P/K у контрольных растений отмечалась тенденция повышения в ряду хвоя - стволик корни. Под воздействием хвойного препарата в дозах $0,03,0,1$ и 0,3 мл м $^{-2}$ соотношение N/P/K в корнях практически не изменялось, а в стволиках отмечалась тенденция повышения в пользу фосфора.

Хвойный препарат оказал положительное влияние на накопление кальция в хвое сеянцев сосны, причем с увеличением дозы препарата содержание кальция в хвое в расчете на единицу сухого вещества возрастало (табл. 2). Уровень кальция повышался также в стволиках при высокой дозе препарата 1,0 мл м $^{-2}$. В хвое опытных растений происходило увеличение содержания цинка и отмечалась тенденция к повышению уровня магния. Под влиянием хвойного препарата при стимулирующих рост растений дозах отмечалась тенденция повышения уровня меди в корнях и стволиках. Известно, что цинк способствует увеличению содержания углеводов и эфирных масел у растений [39]. Соединения меди ускоряют наступление фаз развития у травянистых растений. Медь способствует накоплению у сельскохозяйственных культур каротина, сахаров и минеральных веществ. Влияние хвойного препарата на содержание железа и марганца в стволиках и марганца в корнях сеянцев в расчете на единицу сухого вещества было отрицательным (табл. 2). Было показано, что внесение минеральных удобрений повышало содержание цинка и меди в органах пятилетней сосны обыкновенной, но не оказывало влияния на уровень железа и марганца у растения [40].

Под воздействием хвойного препарата в дозах 0,03, 0,1 и 0,3 мл·м ${ }^{-2}$ вынос и накопление в органах

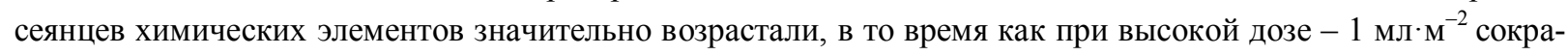
щались до 2 раз по сравнению с контролем, что в основном обусловлено изменением биомассы сеянцев (рис. 2, 3). Особенно значительно препарат повысил накопление фосфора в органах и кальция в хвое и корнях. Препарат оказал стимулирующее влияние на накопление исследуемых микроэлементов в хвое, особенно цинка, при внесении препарата в дозах $0,03-0,3$ мл м $^{-2}$. При использовании хвойного препарата содержание микроэлементов в стволиках и корнях сеянцев в расчете на массу органов одного сеянца повышалось, за исключением марганца и железа в стволиках и марганца - в корнях. При этом максимальное положительное влияние препарат оказал на накопление меди в них.
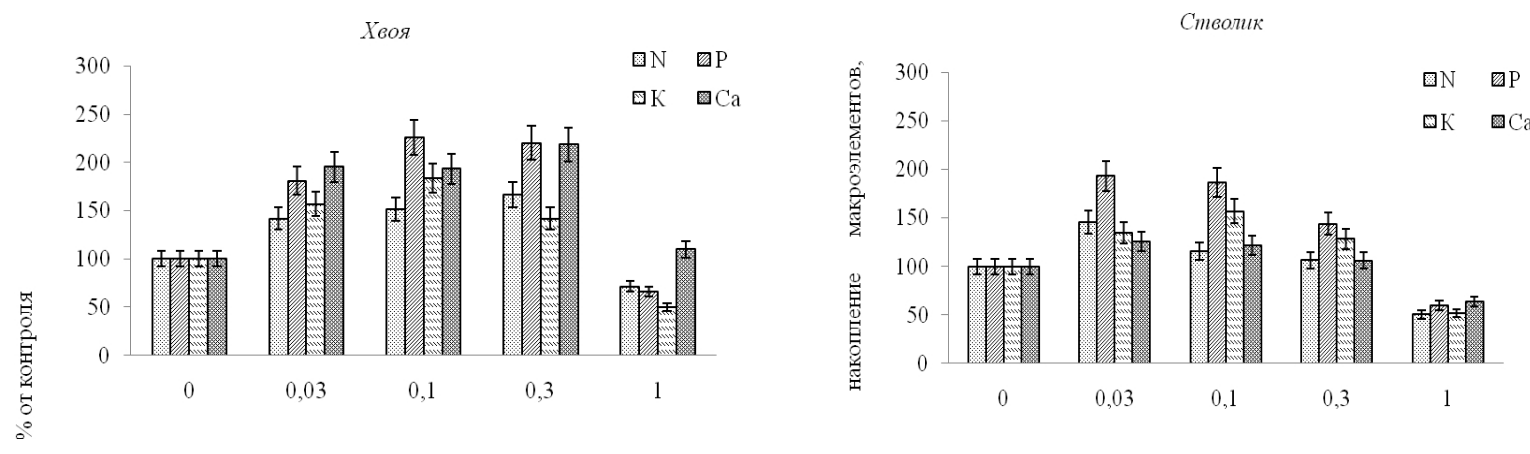

Рис. 2. Влияние хвойного препарата на вынос и накопление макроэлементов в органах двухлетних сеянцев сосны

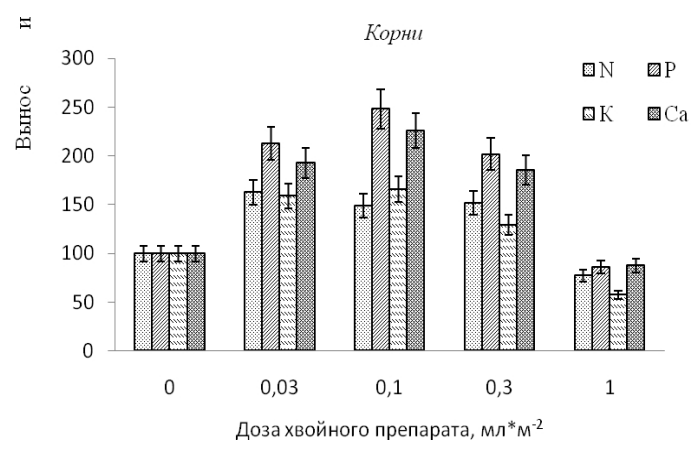



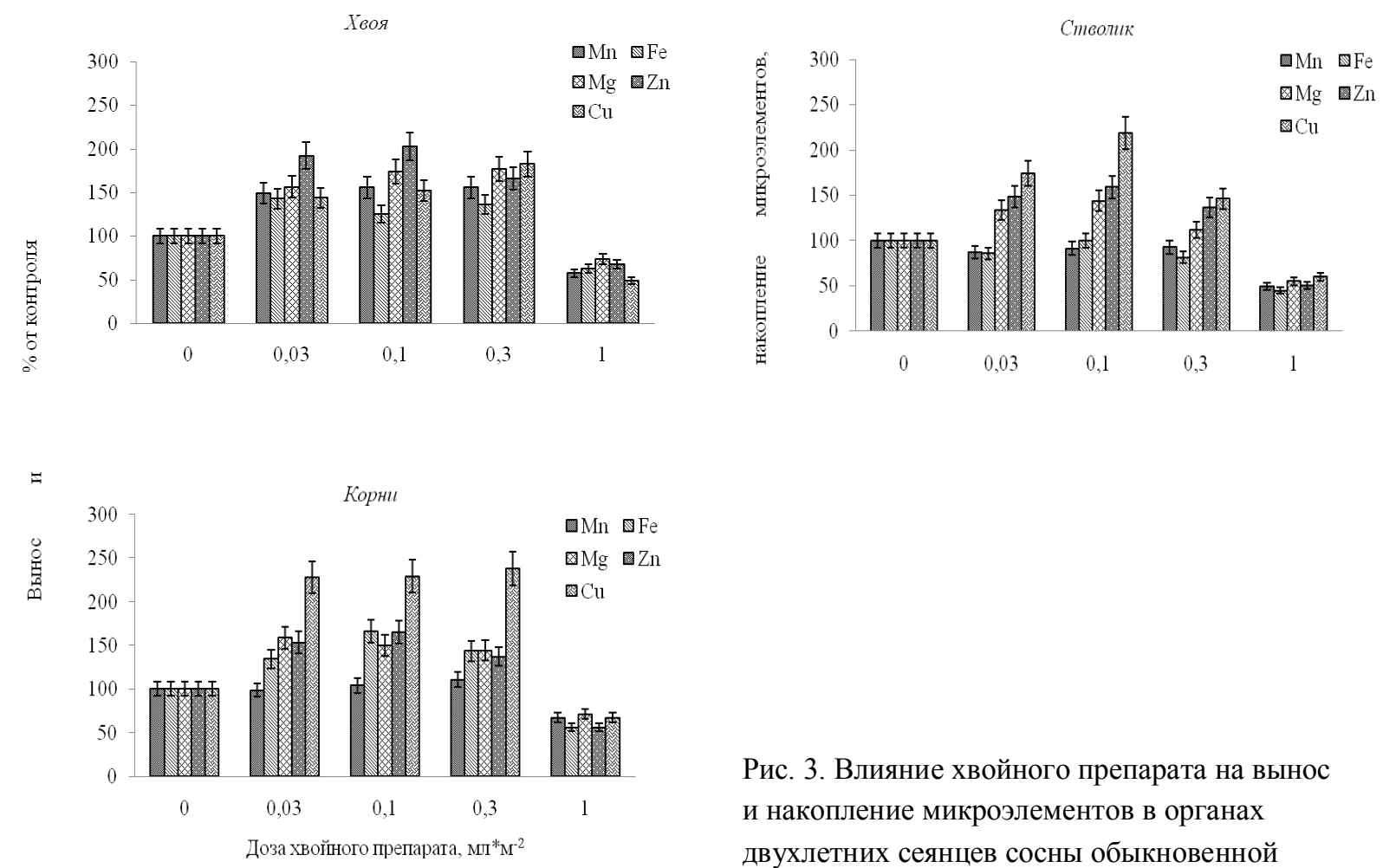

Таким образом, хвойный препарат проявил себя как стимулятор роста, о чем свидетельствует значительное увеличение под его воздействием биометрических показателей сеянцев сосны, а также выноса и накопления в органах большинства макро- и микроэлементов, за исключением марганца в стволиках и корнях и железа в стволиках. В меньшей степени препарат оказал влияние на элементный состав органов сеянцев в расчете на единицу сухой массы, при этом отмечалось повышение или тенденция к повышению уровня фосфора в органах и калия в хвое и корнях, кальция и цинка в хвое, меди - в стволиках и корнях.

Эксперименты по применению органических и минеральных удобрений при выращивании сеянцев сосны обыкновенной и ели европейской в открытом грунте на бедных почвах также не выявили существенного влияния на содержание элементов питания в органах в расчете на единицу сухого вещества $[41,42]$. Можно заключить, что сосна обыкновенная поддерживает свой гомеостаз за счет регуляции интенсивности роста без значительных однозначных изменений концентрации химических элементов в органах.

\section{Выводы}

1. Выявлено стимулирующее действие хвойного препарата на рост растений при внесении в дозах $0,03,0,1$ и 0,3 мл' $\mathrm{m}^{-2}$. Максимальный положительный эффект наблюдался при дозе 0,3 мл $\mathrm{m}^{-2}$. Масса хвои в этом варианте опыта была выше на $121 \%$, масса сеянца - на $109 \%$, а линейные параметры - в 1,5 раза по сравнению с контрольными растениями.

2. Под воздействием препарата увеличивался вынос большинства химических элементов и их накопление в органах сеянцев. Исключение составили марганец по накоплению в стволиках и корнях и железо - в стволиках.

3. Хвойный препарат в стимулирующих рост растений дозах оказал неоднозначное влияние на элементный состав органов сеянцев в расчете на единицу сухого вещества. Отмечалось повышение или тенденция к повышению уровня фосфора в органах, калия в хвое и корнях, меди - в стволиках и корнях, кальция, цинка и магния в хвое.

4. Внесение хвойного препарата в дозах $0,03,0,1$ и 0,3 мл $\cdot \mathrm{M}^{-2}$ способствовало понижению значений соотношения N/P в хвое и стволиках, а также изменяло соотношение N/P/K в хвое сеянцев сосны за счет увеличения доли фосфора, что свидетельствовало об оптимизации статуса фосфора у растений. 
5. Хвойный препарат производства Тихвинского химического завода можно рекомендовать для применения в лесных питомниках в качестве эффективного стимулятора роста при выращивании посадочного материала хвойных пород.

Авторы выражают искреннюю благодарность сотрудникам аналитической лаборатории Тихвинского химического завода за предоставленные образиы хвойного препарата для его испьтания при выращивании посадочного материала хвойных пород.

\section{Сиисок литературы}

1. Yulan Xu, Yuemin Zhang, Yunfei Li, Genqian Li, Daiyi Liu, Minchong Zhao, Nianhui Cai. Growth Promotion of Yunnan Pine Early Seedlings in Response to Foliar Application of IAA and IBA // International Journal of Molecular Sciences. Chine, 2012. Pp. 6507-6520.

2. Пентелькина Ю.С. Влияние стимуляторов на всхожесть семян и рост сеянцев хвойных видов: дис. ... канд. с.-х. наук. М., 2003. 140 c.

3. Кириенко М.А., Гончарова И.А. Влияние концентрации стимуляторов роста на грунтовую всхожесть семян и сохранность сеянцев главных лесообразующих видов Средней Сибири // Сибирский лесной журнал. 2016. № 1. С. 39-45.

4. Пентелькин С.К. Применение Агата-25К в лесном хозяйстве // Лесное хозяйство. 2001. № 2. С. 41-43.

5. Пентелькина Н.В. Применение регулятора роста Циркон при выращивании посадочного материала ценных древесных пород // Циркон - природный регулятор роста. Применение в сельском хозяйстве. М., 2010. C. $330-340$.

6. Пентелькина Н.В. Экологически чистые технологии на основе использования стимуляторов роста // Экология, наука, образование, воспитание. 2002. Вып. 5. С. 69-73.

7. Острошенко В.В., Акимов Р.Ю., Гаман А.В. Эффективность применения стимуляторов роста при выращивании однолетних сеянцев сосны корейской (Pinus koraiensis Siebold et Zucc.) // Вестник Иркутской ГСХА. 2013. Вып. 54. С. 87-93.

8. Острошенко В.В., Ватулич Д.С. Применение стимулятора роста альбит при выращивании сеянцев кедра корейского // Агролесомелиорация и лесное хозяйство. 2014. № 3. С. 144-147.

9. Острошенко В.В., Острошенко Л.Ю., Ключников Д.А., Острошенко В.Ю., Чекушкина Т.Н. Влияние стимуляторов роста на энергию прорастания и лабораторную всхожесть семян сосны обыкновенной (Pinus sylvestris L.) // Известия СамНЦ РАН. 2015. Т. 17. № 6. С. 242-248.

10. Устинова Т.С., Чмурова И.М. Влияние препарата эпин-экстра на ростовые процессы сосны обыкновенной // Актуальные проблемы лесного комплекса. 2011. № 6. С. 153-155.

11. Ковылина О.П., Ковылин Н.В., Кеня Е.С., Познахирко П.Ш. Изучение влияния регуляторов роста на прорастание семян лиственницы сибирской // Актуальные проблемы лесного комплекса. 2014. № 38. С. 93-97.

12. Шакиров Ф.P. Применение крезацина при выращивании сеянцев сосны обыкновенной (Pinus Sylvestris L.) в условиях Башкирского Предуралья : дис. ... канд. биол. наук. Уфа, 2002. 165 с.

13. Зайцева М.И., Робонен Е.В., Чернобровкина Н.П. Использование порубочных остатков для приготовления торфяных субстратов при выращивании сеянцев сосны обыкновенной с закрытой корневой системой // Вестник Московского государственного университета леса - Лесной вестник. 2010. №1. С. 4-8.

14. Зайцева М.И., Робонен Е.В., Чернобровкина Н.П., Колесников Г.Н. Утилизация отходов переработки хвои сосны обыкновенной // Деревянное малоэтажное домостроение: экономика, архитектура и ресурсосберегающие технологии: материалы Международной научно-практической конференции. Петрозаводск, 2013. C. $25-30$.

15. Робонен Е.В., Зайцева М.И., Чернобровкина Н.П., Чернышенко О.В., Васильев С.Б. Опыт разработки и использования контейнерных субстратов для лесных питомников. Альтернативы торфу // Resources and Technology. 2015. № 1. С. 47-76.

16. Васильев С.Н., Рощин В.И., Ягодин В.И. Экстрактивные вещества древесной зелени Pinus sylvestris L. // Pacтительные ресурсы. 1995. Т. 31, вып. 2. С. 79-119.

17. Судачкова Н.Е., Милютина И.Л., Семенова Г.П. Состав и содержание свободных аминокислот в различных частях и тканях Pinus sylvestris L., Larix sibirica ledeb. И L. gmelinii (rupr.) rupr // Растительные ресурсы. 2003. Т. 39, вып. 1. С. 19-31.

18. Фуксман И.Л. Влияние природных и антропогенных факторов на метаболизм веществ вторичного происхождения у древесных растений : дис. ... д-ра биол. наук. Петрозаводск, 2002. 164 с.

19. Чернобровкина Н.П., Дорофеева О.С., Робонен Е.В. Аминокислотный состав хвои сеянцев сосны обыкновенной в связи с обеспеченностью бором // Вестник Московского государственного университета леса - Лесной вестник. 2009. № 3. С. 56-61.

20. Речкина Е.А., Романенко Г.А., Рубчевская Л.П. Выделение пектиновых веществ из древесной зелени сосны обыкновенной // Химия растительного сырья. 2010. № 4. С. 189-190.

21. Meiqiu Z.H.U., Changming M.A., Ying Wang., Lili Zhang., Hui Wang, Yuxin Yuan, Kejiu D.U. Effect of extracts of Chinese pine on its own seed germination and seedling growth // Front. Agric. China, 2009. Pp. 353-358. 
22. Егорова А.В. Влияние хвойного экстракта на проращивание семян сосны обыкновенной // Ресурсосберегающие технологии, материалы и конструкции. Петрозаводск, 2014. С. 38-43.

23. Егорова А.В. Регуляторы роста в процессах прорастания семян и роста сеянцев хвойных пород // Растения в условиях глобальных и локальных природно-климатических и антропогенных воздействий : материалы Всероссийской научной конференции и школы для молодых ученых. Петрозаводск, 2015. С. 183.

24. Широких И.Г. Влияние терпеновых соединений на ростовые и физиолого-биохимические показатели проростков пшеницы // Новые достижения в химии и химической технологии растительного сырья : материалы III Всероссийской конференции. Барнаул, 2007. Кн. 3. С. 240-245.

25. Карманова Л.И., Кучин А.В., Королева А.А., Хуршкайнен Т.В., Кучин В.А. Экстракция водным раствором оснований как основа новой технологии получения фунгицидов и стимуляторов роста растений // Химия и компьютерное моделирование. Бутлеровские сообщения. 2002. № 7. С. 61-64.

26. Кирсанова Е.В., Цуканова 3.Р., Мусалатова Н.Н. О перспективах предпосевной обработки регуляторами роста семян яровой пшеницы в Орловской области // Вестник ОрелГАУ. 2008. № 3. С. 21-23.

27. Хуршкайнен Т.В. Выделение и исследование кислых компонентов липидов древесной зелени пихты (Abies sibirica) и ели (Picea sibirica) : автореф. дис. ... канд. хим. наук. Сыктывкар, 2004. 24 с.

28. Ушанова В.М. Комплексная переработка древесной зелени и коры пихты сибирской с получением продуктов, обладающих биологической активностью : автореф. дис. ... д-ра биол. наук. Красноярск, 2012. 34 с.

29. Чернобровкина Н.П. Экофизиологическая характеристика использования азота сосной обыкновенной. СПб., 2001. $175 \mathrm{c}$.

30. Аринушкина С.В. Руководство по химическому анализу почв. М., 1970. 487 с.

31. Зайцев Г.Н. Математическая статистика в экспериментальной ботанике. М., 1984. 424 с.

32. Ивантер Э.В., Коросов А.В. Введение в количественную биологию. Петрозаводск, 2003. 304 с.

33. Тебенькова Д.Н., Лукина Н.В., Воробьев Р.А., Орлова М.А. Всхожесть семян и биометрические показатели сеянцев на субстратах из твердых отходов целлюлозно-бумажной промышленности // Лесоведение. 2014. № 6. C. 31-40.

34. Indestad T. Macro element nutrition of pine, spruce, and birch seedlings in nutrient solutions // Medd. Staters skogsfarskingsinst 1962-1963. Vol. 51. N 7. 150 p.

35. Чулагулова 3.С. Почвы лесных питомников и пути их рационального использования. М., 1974. $144 \mathrm{c.}$

36. Вахмистров Д.Б., Воронцов В.А. Соотношение элементов минерального питания в среде и рост растений. 3 . Корреляционное зондирование купола отклика // Физиология растений. 1994. Т. 41. № 3. С. 425-429.

37. Сазонова Т.А., Придача В.Б. Оптимизация минерального питания хвойных растений // Агрохимия. 2002. № 2. C. $23-30$.

38. Придача В.Б., Сазонова Т.А. Возрастные изменения содержания и соотношения азота, фосфора и калия в органах Pinus sylvestris L. и Picea abies (Pinaceae) // Ботанический журнал. 2004. Т. 89. № 9. С. 1486-1496.

39. Битюцкий Н.П. Микроэлементы высших растений. СПб., 2001. 368 с.

40. Sienkiewicz A. Wplaw nawozenia mineralnego i Wapnowania na biologiczna acumulacje microelementow przez sosne zwyczajna (Pinus sylvestris L.) // Rocz. AR Pozn. Lesn. 1981. N 18. Pp. 153-163.

41. Чернобровкина Н.П., Васильева Э.С., Успенская Л.Н. Влияние подкормок минеральными удобрениями на рост и элементный химический состав сеянцев сосны. Петрозаводск, 1990. С. 58-67.

42. Мамаев А.А., Романов Е.М., Мухортов Д.И. Оценка эффективности использования элементов питания сеянцами древесных растений на слабоокультуренных дерново-подзолистых почвах // Вестник ПГТУ. 2011. № 1. C. 11-18. 
Egorova A.V.*, Chernobrovkina N.P., Robonen E.V. EFFECTS OF APPLICATION OF A CONIFER-DERIVED CHEMICAL ON THE GROWTH AND ELEMENTAL COMPOSITION OF PINUS SYLVESTRIS L. SEEDLINGS IN A FOREST NURSERY

\section{Forest Research Institute, Karelian Research Centre, Russian Academy of Sciences, ul. Pushkinskaya,11,Petrozavodsk, 185910 (Russia),e-mail:egorova.anast@mail.ru}

A conifer-derived chemical produced by Tikhvinsky chemicals plant was tested for its effects on the growth and storage of nutrients in 2-year-old Scots pine seedlings raised in open field conditions in a forest nursery. The dosages of $0.03,0.1$ and $0.3 \mathrm{ml} \cdot \mathrm{m}^{-2}$ were found to promote plant growth. The highest positive effect on the seedlings' growth was observed when the dosage was $0.3 \mathrm{ml} \cdot \mathrm{m}^{-2}$. In these treatments, the weight of needles exceeded the control by $121 \%$, seedlings' weight exceeded it by $109 \%$, and the seedlings' dimensions increased 1.5-fold at maximum. The chemical promoted the uptake of most nutrients and their storage in seedlings' organs. The exceptions were manganese and iron in stems and manganese in roots. The conifer-derived chemical applied in growth-stimulating doses had non-uniform effects on the elemental composition of the seedlings' organs per unit dry weight. We observed an increase or an upward trend of phosphorus level in organs, potassium in needles and roots, copper in stems and roots, calcium, zinc and magnesium in needles. Placements of the chemical in $0.03,0.1$ and $0.3 \mathrm{ml} / \mathrm{m}^{-2}$ doses resulted in a reduction of the N/P ratio in needles and stems, and modified the N/P/K ratio in needles of pine seedlings owing to an increase in the proportion of phosphorus, proving the plants' phosphorus status was optimized. This conifer-derived chemical can be recommended for use in forest nurseries as an effective growth stimulant for coniferous stocking material.

Keywords: Pinus sylvestris L., seedlings, growth, growth regulators, elemental composition, conifer-derived chemical, fertilizer placement, forest nursery

\section{References}

1. Yulan Xu, Yuemin Zhang, Yunfei Li, Genqian Li, Daiyi Liu, Minchong Zhao, Nianhui Cai. International Journal of Molecular Sciences, Chine, 2012, pp. 6507-6520.

2. Pentel'kina Iu.S. Vliianie stimuliatorov na vskhozhest' semian i rost seiantsev khvoinykh vidov: dis. ... kand. s. $-k h$. $n a u k$. [Influence of stimulants on seed germination and growth of conifer species: diss. Candidate of Agricultural Sciences]. Moskva, 2003, 140 p. (in Russ.).

3. Kirienko M.A., Goncharova I.A. Sibirskii lesnoi zhurnal, 2016, no. 1, pp. 39-45. (in Russ.).

4. Pentel'kin S.K. Lesnoe khoziaistvo, 2001, no. 2, pp. 41-43. (in Russ.).

5. Pentel'kina N.V. Tsirkon - prirodnyi reguliator rosta. Primenenie v sel'skom khoziaistve. [Zircon is a natural growth regulator. Application in agriculture]. Moscow, 2010, pp. 330-340. (in Russ.).

6. Pentel'kina N.V. Ekologiia, nauka, obrazovanie, vospitanie, 2002, no. 5, pp. 69-73. (in Russ.).

7. Ostroshenko V.V., Akimov R.Iu., Gaman A.V. Vestnik Irkutskoi GSKhA, 2013, no. 54, pp. 87-93. (in Russ.).

8. Ostroshenko V.V., Vatulich D.S. Agrolesomelioratsiia i lesnoe khoziaistvo, 2014, no. 3, pp. 144-147. (in Russ.).

9. Ostroshenko V.V., Ostroshenko L.Iu., Kliuchnikov D.A., Ostroshenko V.Iu., Chekushkina T.N. Izvestiia SamNTs $R A N$, 2015, vol. 17, no. 6, pp. 242-248. (in Russ.).

10. Ustinova T.S., Chmurova I.M. Aktual'nye problemy lesnogo kompleksa, 2011, no. 6, pp. 153-155. (in Russ.).

11. Kovylina O.P., Kovylin N.V., Kenia E.S., Poznakhirko P.Sh. Aktual'nye problemy lesnogo kompleksa, 2014, no. 38, pp. 93-97. (in Russ.).

12. Shakirov F.R. Primenenie krezatsina pri vyrashchivanii seiantsev sosny obyknovennoi (Pinus Sylvestris L.) $v$ usloviiakh Bashkirskogo Predural'ia: dis. ... kand. biol. nauk. [The use of krezacin in the cultivation of Pinus sylvestris L. seedlings (Pinus Sylvestris L.) in the conditions of the Bashkir Preduralye: dis. ... cand. Biol. Sciences]. Ufa, 2002, 165 p. (in Russ.).

13. Zaitseva M.I., Robonen E.V., Chernobrovkina N.P. Vestnik Moskovskogo gosudarstvennogo universiteta lesa Lesnoi vestnik, 2010, no. 1, pp. 4-8. (in Russ.).

14. Zaitseva M.I., Robonen E.V., Chernobrovkina N.P., Kolesnikov G.N. Dereviannoe maloetazhnoe domostroenie: ekonomika, arkhitektura i resursosberegaiushchie tekhnologii: materiala mezhdunarodnoi nauchno-prakticheskoi konferentsii. [Wooden low-rise housing construction: economics, architecture and resource-saving technologies: the material of the international scientific-practical conference]. Petrozavodsk, 2013, pp. 25-30. (in Russ.).

15. Robonen E.V., Zaitseva M.I., Chernobrovkina N.P., Chernyshenko O.V., Vasil'ev S.B. Resources and Technology, 2015, no. 1, pp. 47-76. (in Russ.).

16. Vasil'ev S.N., Roshchin V.I., Iagodin V.I. Rastitel'nye resursy, 1995, vol. 31, no. 2, pp. 79-119. (in Russ.).

17. Sudachkova H.E., Miliutina I.L., Semenova G.P. Rastitel'nye resursy, 2003, vol. 39, no. 1, pp. 19-31. (in Russ.).

18. Fuksman I.L. Vliianie prirodnykh i antropogennykh faktorov na metabolizm veshchestv vtorichnogo proiskhozhdeniia $u$ drevesnykh rastenii: dis. ... dokt. biol. nauk. [The influence of natural and anthropogenic factors on the metabolism of substances of secondary origin in woody plants: dis. ... Doct. Biol. Sciences.]. Petrozavodsk, 2002, 164 p. (in Russ.).

19. Chernobrovkina N.P., Dorofeeva O.S., Robonen E.V. Vestnik Moskovskogo gosudarstvennogo universiteta lesa Lesnoi vestnik, 2009, no. 3, pp. 56-61. (in Russ.).

20. Rechkina E.A., Romanenko G.A., Rubchevskaia L.P. Khimiia rastitel'nogo syr'ia, 2010, no. 4, pp. 189-190. (in Russ.).

\footnotetext{
${ }^{*}$ Corresponding author.
} 
21. Meiqiu Z.H.U., Changming M.A., Ying Wang., Lili Zhang., Hui Wang, Yuxin Yuan, Kejiu D.U. Front. Agric., China, 2009, pp. 353-358.

22. Egorova A.V. Resursosberegaiushchie tekhnologii, materialy i konstruktsii. [Resource-saving technologies, materials and structures]. Petrozavodsk, 2014, pp. 38-43. (in Russ.).

23. Egorova A.V. Rasteniia v usloviiakh global'nykh i lokal'nykh prirodno-klimaticheskikh i antropogennykh vozdeistvii: materialy Vserossiiskoi nauchnoi konferentsii i shkoly dlia molodykh uchenykh. [Plants in the conditions of global and local natural, climatic and anthropogenic influences: the materials of the All-Russian Scientific Conference and the School for Young Scientists]. Petrozavodsk, 2015, p. 183. (in Russ.).

24. Shirokikh I.G. Novye dostizheniia $v$ khimii i khimicheskoi tekhnologii rastitel'nogo syr'ia: materialy III Vserossiiskoi konferentsii. [New achievements in chemistry and chemical technology of plant raw materials: materials of the III All-Russian Conference]. Barnaul, 2007, vol. 3, pp. 240-245. (in Russ.).

25. Karmanova L.I., Kuchin A.V., Koroleva A.A., Khurshkainen T.V., Kuchin V.A. Khimiia i komp'iuternoe modelirovanie. Butlerovskie soobshcheniia, 2002, no. 7, pp. 61-64. (in Russ.).

26. Kirsanova E.V., Tsukanova Z.R., Musalatova N.N. Vestnik OrelGAU, 2008, no. 3, pp. 21-23. (in Russ.).

27. Khurshkainen T.V. Vydelenie i issledovanie kislykh komponentov lipidov drevesnoi zeleni pikhty (Abies sibirica) $i$ eli (Picea sibirica): avtoref. dis. ... kand. khim. nauk. [Isolation and study of acidic components of the lipids of the fir tree of fir (Abies sibirica) and spruce (Picea sibirica): Abstract. Dis. ... cand. Chem. Sciences]. Syktyvkar, 2004, 24 p. (in Russ.).

28. Ushanova V.M. Kompleksnaia pererabotka drevesnoi zeleni i kory pikhty sibirskoi s polucheniem produktov, obladaiushchikh biologicheskoi aktivnost'iu: avtoref. dis. ... dokt. biol. nauk. [Complex processing of woody greens and Siberian fir bark with the production of products with biological activity: author's abstract. Dis. ... Doct. Biol. Of sciences]. Krasnoiarsk, 2012, 34 p. (in Russ.).

29. Chernobrovkina N.P. Ekofiziologicheskaia kharakteristika ispol'zovaniia azota sosnoi obyknovennoi. [Ecophysiological characteristics of the use of nitrogen pine]. St. Petersburg, 2001, 175 p. (in Russ.).

30. Arinushkina S.V. Rukovodstvo po khimicheskomu analizu pochv. [Guidelines for the chemical analysis of soils]. Moscow, 1970, 487 p. (in Russ.).

31. Zaitsev G.N. Matematicheskaia statistika v eksperimental'noi botanike. [Mathematical statistics in experimental botany]. Moscow, 1984, 424 p. (in Russ.).

32. Ivanter E.V., Korosov A.V. Vvedenie $v$ kolichestvennuiu biologiiu. [Introduction to quantitative biology]. Petrozavodsk, 2003, 304 p. (in Russ.).

33. Teben'kova D.N., Lukina N.V., Vorob'ev R.A., Orlova M.A. Lesovedenie, 2014, no. 6, pp. 31-40. (in Russ.).

34. Indestad T. Medd. Staters skogsfarskingsinst 1962-1963, vol. 51, no. 7, 150 p.

35. Chulagulova Z.S. Pochvy lesnykh pitomnikov i puti ikh ratsional'nogo ispol'zovaniia. [Soils of forest nurseries and ways of their rational use]. Moscow, 1974, 144 p. (in Russ.).

36. Vakhmistrov D.B., Vorontsov V.A. Fiziologiia rastenii, 1994, vol. 41, no. 3, pp. 425-429. (in Russ.).

37. Sazonova T.A., Pridacha V.B. Agrokhimiia, 2002, no. 2, pp. 23-30. (in Russ.).

38. Pridacha V.B., Sazonova T.A. Botanicheskii zhurnal, 2004, vol. 89, no. 9, pp. 1486-1496. (in Russ.).

39. Битюцкий Н.П. Микроэлементы высших растений. СПб., 2001. 368 с. (in Russ.).

40. Sienkiewicz A. Rocz. AR Pozn. Lesn., 1981, no. 18, pp. 153-163.

41. Chernobrovkina N.P., Vasil'eva E.S., Uspenskaia L.N. Vliianie podkormok mineral'nymi udobreniiami na rost $i$ elementnyi khimicheskii sostav seiantsev sosny. [Influence of fertilizing with mineral fertilizers on the growth and elemental chemical composition of pine seedlings]. Petrozavodsk, 1990, pp. 58-67. (in Russ.).

42. Mamaev A.A., Romanov E.M., Mukhortov D.I. Vestnik PGTU., 2011, no. 1, pp. 11-18. (in Russ.). 